University of Nebraska - Lincoln

DigitalCommons@University of Nebraska - Lincoln

Faculty Publications - Chemistry Department Published Research - Department of Chemistry

2020

\title{
A Luminescence-Based System for Identification of Genetically Encodable Inhibitors of Protein Aggregation
}

Travis J. Nelson

Shuo Liang

Cliff I. Stains

Follow this and additional works at: https://digitalcommons.unl.edu/chemfacpub

Part of the Analytical Chemistry Commons, Medicinal-Pharmaceutical Chemistry Commons, and the Other Chemistry Commons

This Article is brought to you for free and open access by the Published Research - Department of Chemistry at DigitalCommons@University of Nebraska - Lincoln. It has been accepted for inclusion in Faculty Publications -Chemistry Department by an authorized administrator of DigitalCommons@University of Nebraska - Lincoln. 


\title{
A Luminescence-Based System for Identification of Genetically Encodable Inhibitors of Protein Aggregation
}

\author{
Travis J. Nelson, Shuo Liang, and Cliff I. Stains*
}

Cite This: ACS Omega 2020, 5, 12974-12978

Read Online

ABSTRACT: Molecules that disrupt protein aggregation represent potential tool compounds for the investigation of numerous human disease states. However, the identification of small molecules capable of disrupting protein aggregation has proven challenging. Larger biomolecules such as antibodies and proteins are promising alternatives due to their increased size. Despite the promise of protein-based inhibitors, generalizable assays are needed to more readily identify proteins capable of inhibiting aggregation. Herein, we utilize our previously reported selfassembling NanoLuc luciferase fragments to engineer a platform in which both detection reagents are expressed from the same plasmid, enabling facile co-transformation with a genetically encodable inhibitor. This streamlined system is capable of detecting changes in the solubility of amylin, huntingtin, and amyloid- $\beta(\mathrm{A} \beta)$ proteins in response to mutations, small-molecule inhibitors, and expression of genetically encodable inhibitors. This improved platform provides a means to begin to identify protein-based inhibitors with improved efficacy.

\section{INTRODUCTION}

Protein aggregation and the formation of insoluble protein fibrils are associated with numerous human diseases. ${ }^{1,2}$ This has motivated several efforts to identify small-molecule inhibitors of protein aggregation. ${ }^{3}$ Although powerful tools, small-molecule inhibitors suffer from relatively limited surface areas, hindering their ability to disrupt protein-protein interactions. Alternatively, protein-based inhibitors provide the potential to disrupt interactions involving large surface areas. $^{2-5}$ However, a lack of assays capable of identifying protein-based inhibitors of aggregation that function in cellular environments has limited progress in this area.

Early strategies for the detection of protein aggregates relied on staining with small molecules, such as thioflavin $\mathrm{T}$ and congo red, capable of producing a change in optical signal in the presence of aggregates. ${ }^{6-9}$ These small-molecule probes remain powerful tools to analyze protein aggregation in vitro but have limited utility in cellular applications and can produce false positives when screening for inhibitors of fibrillization. ${ }^{10}$ To address this issue, genetically encodable reporters of protein aggregation have been developed. ${ }^{1-15}$ These reporters generally rely on using the aggregation of an appended proteinof-interest to modulate the function of a reporter (Figure 1a). In an elegant example, a GFP-based folding reporter has been used to identify small-molecule inhibitors of $\mathrm{A} \beta$ aggregation. ${ }^{16-18}$ As a complementary approach to monitor protein aggregation, we have utilized self-assembling fragments of NanoLuc luciferase (Nluc). ${ }^{19-22}$ Nluc is a small (19 kDa), engineered luciferase $^{23,24}$ and provides a robust platform for

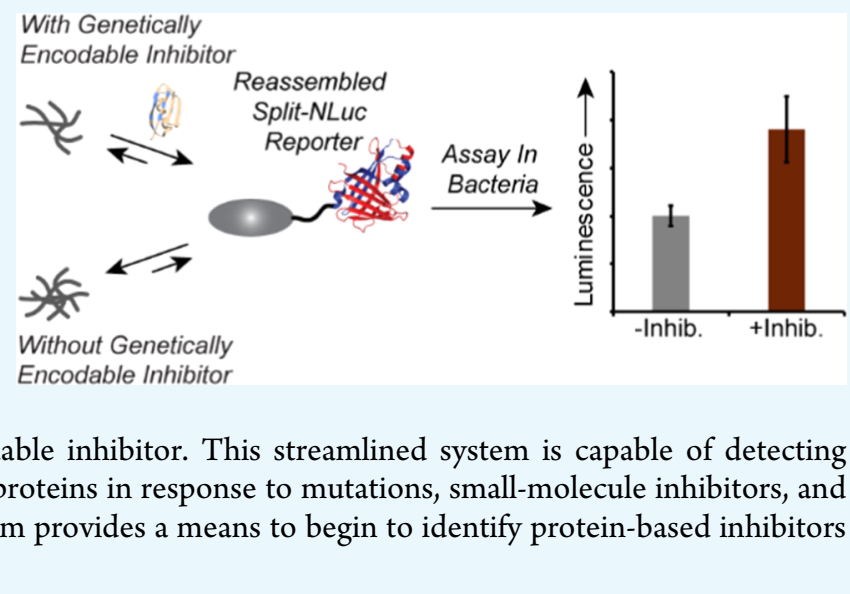

With Genetically

Encodable Inhibitor

Without Genetically -Inhib. +Inhib. engineering luminescence reporter assays. ${ }^{25,26} \mathrm{We}$ have previously identified Nluc fragments termed N65 (residues 1-65) and 66C (residues 66-171) that are capable of spontaneous reassembly to afford functional enzyme. ${ }^{20}$ Fusion of a protein-of-interest (POI) to the N-terminus of N65 results in a change in the amount of N65 available for reassembly that is proportional to the solubility of the POI. Using this approach, relative changes in the solubility of the POI as a result of point mutants or treatment with small-molecule inhibitors can be assessed (Figure $1 \mathrm{~b}$ ). Our previous platform relied on the coexpression of POI-N65 and 66C reporter constructs from different plasmids, complicating the identification of genetically encodable inhibitors. Herein, we reengineer this system using a single plasmid to drive expression of both reporter components (Figure 1c). This re-engineered system is used to monitor the solubility of amylin, huntingtin, and $\mathrm{A} \beta$ proteins and is capable of reporting on the relative influence of mutations, small-molecule inhibitors, and proteinbased inhibitors on aggregation.

Received: February 21, 2020

Accepted: May 15, 2020

Published: May 29, 2020 

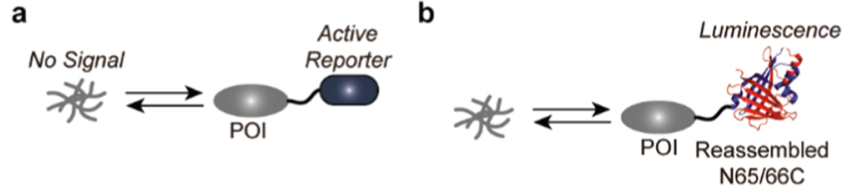

C
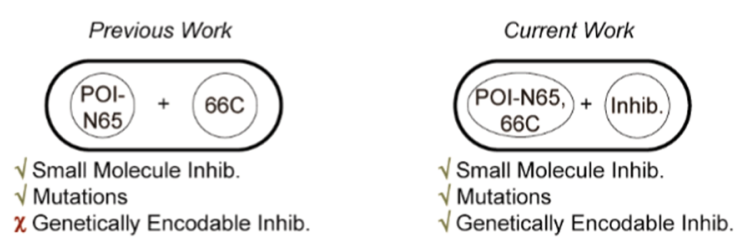

Figure 1. Cell-based assay systems for detecting protein solubility. (a) A reporter capable of producing an observable signal is fused to the $\mathrm{C}$ terminus of a protein-of-interest (POI). The activity of the reporter protein is modulated by the equilibrium between the folded and unfolded states. (b) A POI is fused to the N-terminus of N65 (blue). The equilibrium between folded and unfolded protein dictates the amount of $\mathrm{N} 65$ available for reassembly with $66 \mathrm{C}$ (red). Reassembled $\mathrm{N} 65 / 66 \mathrm{C}$ produces a luminescent signal that is proportional to the amount of soluble POI. (c) The previously described split-Nluc assay system was based on two expression plasmids for POI-N65 and 66C. ${ }^{20}$ The re-engineered split-Nluc assay system utilizes a single plasmid to drive the expression of both POI-N65 and 66C proteins, allowing for the interrogation of genetically encodable inhibitors.

\section{RESULTS AND DISCUSSION}

In order to investigate the ability to identify protein-based inhibitors of aggregation, we first examined whether coexpression of our reporter system from the same plasmid was feasible. For this purpose, we chose the commercially available pETDuet-1 vector, which is compatible with P15A, Mini-F/ RK2, CloDF13, RSF1030, or ColA replicons. We examined whether mutations known to increase the solubility of amylin could be detected in this new system. Importantly, we have previously shown that our split-Nluc fragments are capable of reporting on the relative increase in the solubility of the I26P mutant of amylin ${ }^{27}$ when expressed from separate plasmids. ${ }^{21}$ Accordingly, wild-type (wt) amylin or the I26P mutant were fused to the $\mathrm{N}$-terminus of $\mathrm{N} 65$ in the $5^{\prime}$ multiple cloning site of pETDuet-1 (Table S1). The 66C Nluc fragment was cloned into the $3^{\prime}$ multiple cloning site of pETDuet-1 (Table S1). These coexpression constructs were transformed into bacteria, expression was induced by addition of IPTG, and samples were normalized to cell density prior to luminescence analysis in intact cells. The $\mathrm{I} 26 \mathrm{P}$ mutant showed an increase of 2.3 -fold in the luminescence signal, similar to our lab's previously reported results using separate expression plasmids (Figure $2) .^{21}$ This result suggests that our re-engineered, single-plasmid system retains the ability to detect changes in protein solubility.

Building upon this observation, we next asked whether this system could detect the influence of small-molecule inhibitors of protein aggregation. Our lab has previously used the splitNluc reporters ${ }^{21}$ to validate the inhibition of amylin aggregation by silibinin ${ }^{28}$ as well as the inhibition of huntingtin protein $(\mathrm{Htt})$ aggregation by cystamine. ${ }^{29-31}$ To investigate the ability of our re-engineered platform to report on changes in $\mathrm{Htt}$ solubility, we fused a mutant of $\mathrm{Htt}$ containing 97 glutamine repeats ( $\mathrm{Htt97Q}$ ) to the N-terminus of N65. ${ }^{32-34}$ When expression was induced with IPTG and samples were normalized for cell densities, we observed an increase in luminescence in cells incubated with their respective inhibitors KCNTATCATQRLANFLVHSSNNFGAILSSTNVGSNTY

b

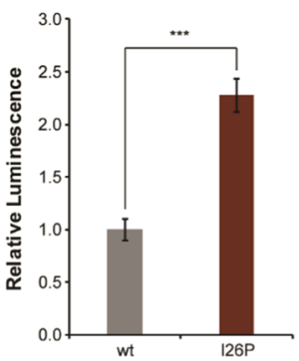

Figure 2. Monitoring the influence of mutations on amylin solubility using the single-plasmid split-Nluc assay. (a) The amino acid sequence of amylin is shown with the mutation site indicated in red. (b) A dramatic increase in the luminescence of bacterial cells expressing the I26P mutant is observed relative to cells expressing wild-type (wt) protein using the Nano-Glo Live Cell Assay reagent. Error bars represent the standard deviation of three biological replicates assayed in triplicate. ${ }^{* * *}$ indicates a $p$-value of $<0.001$.

that was consistent with our previously reported data using two reporter plasmids (Figure 3). ${ }^{21}$ These experiments indicate that our re-engineered coexpression platform can be utilized to identify small-molecule inhibitors of protein aggregation.

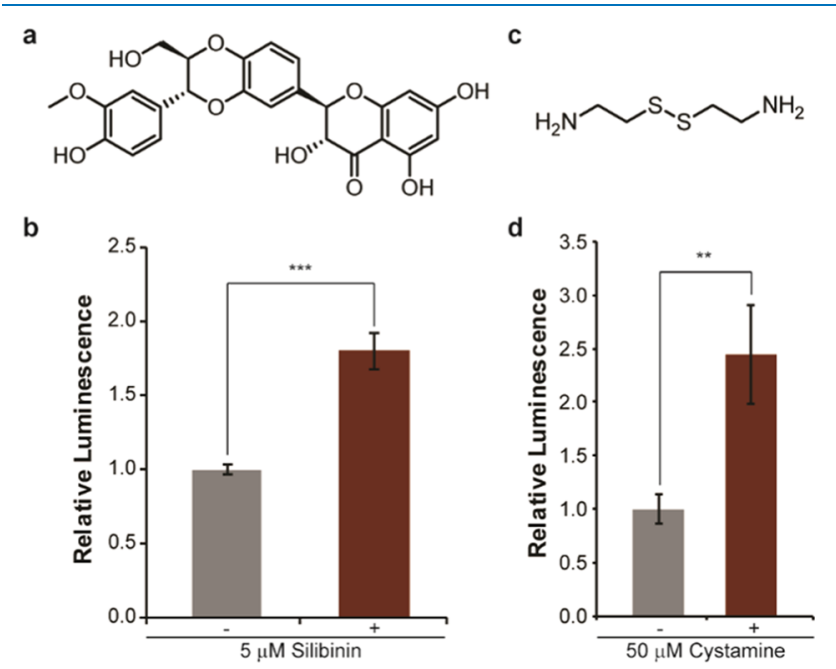

Figure 3. Monitoring the influence of small molecules on protein solubility using the single-plasmid split-Nluc assay. (a) The structure of silibinin, a known inhibitor of amylin aggregation, is shown. (b) Luminescence from bacterial cells expressing amylin-N65/66C in the presence or absence of silibinin using coelenterazine as the substrate. (c) The structure of cystamine, a known inhibitor of Htt aggregation, is shown. (d) Luminescence from bacterial cells expressing Htt97QN65/66C in the presence or absence of cystamine using coelenterazine as the substrate. Error bars represent the standard deviation of three biological replicates assayed in triplicate. ** indicates a $p$-value of $<0.01$ and $* * *$ indicates a $p$-value of $<0.001$.

Encouraged by these results, we sought to determine whether the re-engineered platform was also capable of assessing the influence of genetically encodable inhibitors on protein aggregation. As a proof-of-concept system, we chose the evolved miniprotein known as TJ10 (Table S1). ${ }^{35}$ TJ10 is a variant of the hyperthermophilic mutant of the IgG-binding protein $(\mathrm{HTB} 1)^{36}$ that was evolved via phage display to bind to $\mathrm{A} \beta$ oligomers and disrupt aggregation in vitro. We have 
previously reported the ability of the split-Nluc assay system to detect changes in $\mathrm{A} \beta_{1-42}$ aggregation upon treatment of lysates with $o$-vanillin. ${ }^{20}$ However, this small-molecule inhibitor was found to be toxic to living cells at the concentrations required for inhibition of $\mathrm{A} \beta_{1-42}$ aggregation. In the long term, we hypothesize that our re-engineered system may allow for the identification of protein-based inhibitors of $\mathrm{A} \beta_{1-42}$ aggregation with reduced toxicity. Toward this goal, $\mathrm{A} \beta_{1-42}$ was fused to the N-terminus of N65 in the dual-expression vector and TJ10 was subsequently cloned into the $5^{\prime}$ cloning site of a complementary expression vector, pRSFDuet-1, containing a RSF1030 replicon (Table S1). We hypothesized that the use of a higher-copy plasmid as well as a $\mathrm{T} 7$ promoter for the genetically encodable inhibitor would saturate the split-Nluc reporter system, potentially enabling identification of weak inhibitors in future experiments. Bacteria were then either transformed with the $\mathrm{A} \beta_{1-42}-\mathrm{N} 65 / 66 \mathrm{C}$ dual-expression system alone or co-transformed with the plasmid expressing TJ10. Bacterial cultures were induced with IPTG, normalized for cell density, and intact cells were assayed for changes in luminescence. We observed a significant $90 \%$ increase in luminescence when $\mathrm{TJ} 10$ was co-expressed with the $\mathrm{A} \beta_{1-42^{-}}$ N65/66C detection system (Figure 4). Given the higher copy
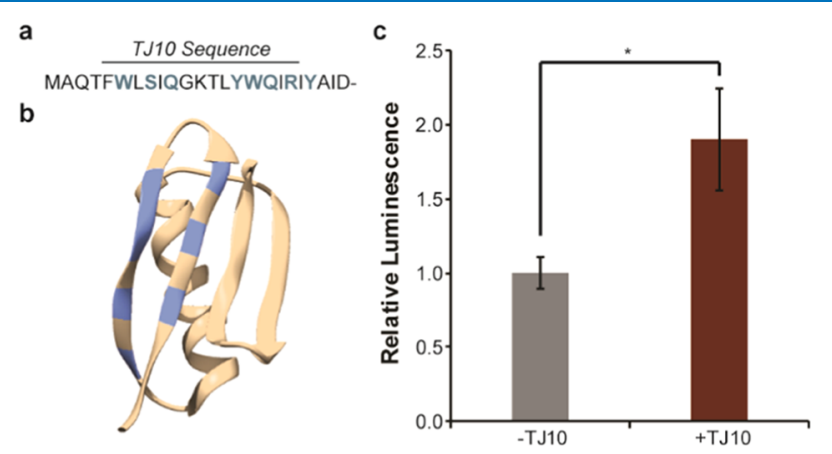

Figure 4. Monitoring inhibition of $\mathrm{A} \beta_{1-42}$ aggregation in bacterial cells using a genetically encodable inhibitor. (a) The amino acid sequence of the first two $\beta$-strands of TJ10 with the residues selected for binding to $\mathrm{A} \beta$ shown in blue. (b) A structural model of $\mathrm{TJ} 10$ (based on HTB1, PDB: 1GB4) with the positions of the mutated residues shown in blue. (c) A clear increase in the luminescence of cells expressing $\mathrm{TJ} 10$ is observed using furimazine as the substrate. Error bars represent the standard deviation of three biological replicates assayed in triplicate. ${ }^{*}$ indicates a $p$-value of $<0.05$.

number of the pRSFDuet-1 plasmid, we investigated whether TJ10 was present at saturating concentrations within cells. This was confirmed by cloning a second copy of TJ10 into the $3^{\prime}$ site of pRSFDuet-1, the resulting dual-TJ10 expression vector yielded a similar luminescence increase to the single-copy plasmid (Figure S1). Interestingly, expression of TJ10 in the amylin and $\mathrm{Htt97Q}$ reporter systems resulted in 20 and $46 \%$ increases in luminescence, respectively (Figure S2). This may indicate that TJ10 recognizes common oligomeric structures shared by these proteins and $\mathrm{A} \beta_{1-42}$, similar to previously described oligomer-specific antibodies. ${ }^{37}$ Taken together, these experiments demonstrate that our re-engineered assay platform can be utilized for the straightforward interrogation of genetically encoded inhibitors of protein aggregation.

\section{CONCLUSIONS}

We have re-engineered a split-Nluc platform to utilize a single coexpression plasmid to drive production of the detection constructs. This platform is capable of detecting changes in protein solubility resulting from mutations as well as addition of small molecules. The assay retained its functionality for detecting amylin, huntingtin, and $\mathrm{A} \beta$ protein aggregation. Building upon the ease of co-transformation in this system, we demonstrated the ability to interrogate the influence of genetically encodable inhibitors on protein aggregation. Previous work has demonstrated that the split-Nluc system is capable of producing a $>10$-fold change in luminescent signal depending on the solubility of the protein fused to $\mathrm{N} 65,{ }^{20}$ thus we expect that the systems described herein can be used directly for identification of inhibitors. Efforts to further improve the dynamic range of the assay are focused on increasing the reassembly efficiency of $\mathrm{N} 65$ and 66C, which is currently $\sim 0.1 \%{ }^{20}$ Given the ability to generate DNA libraries of mutant proteins and peptides, ${ }^{38-41}$ we anticipate that these new assay systems could potentially be used in their current form to identify protein-based inhibitors of protein aggregation.

\section{METHODS}

Small-Molecule Inhibitor Stocks. Silibinin (amylin aggregation inhibitor) was prepared as a $200 \times$ stock solution at a concentration of $1 \mathrm{mM}$ in dimethyl sulfoxide (DMSO). Cystamine (Htt aggregation inhibitor) was prepared as a $1000 \times$ stock solution at $50 \mathrm{mM}$ in water.

Cloning of N65 Fusions and 66C into pETDuet-1. Sequences for $\mathrm{A} \beta_{1-42}-\mathrm{N} 65$, amylin-N65, Htt97Q-N65, and 66C were amplified from previously described vectors. ${ }^{20,21}$ DNA sequences encoding for N-terminal fusions to N65 were cloned into the first multiple cloning site of the pETDuet-1 vector (Novagen, TB337) using primers containing 5' NcoI and $3^{\prime}$ NotI restriction sites. The DNA sequence corresponding to the C-terminal Nluc fragment (residues 66-171) was then incorporated into the second multiple cloning site using primers containing $5^{\prime} \mathrm{NdeI}$ and $3^{\prime} \mathrm{XhoI}$ restriction sites. Ligated DNA was transformed into XL1-Blue competent cells (Agilent, \#200249) and amplified on LB plates containing ampicillin $(100 \mu \mathrm{g} / \mathrm{mL})$. The amylin I26P mutant was generated using site-directed mutagenesis according to the manufacture's protocol (QuikChange XL Site-Directed Mutagenesis Kit, Agilent, \#200517). Plasmids were verified by DNA sequencing.

Cloning of TJ10 into pRSFDuet-1. A DNA sequence encoding for $\mathrm{TJ} 10^{35}$ was cloned into the first multiple cloning site of the pRSFDuet-1 vector (Novagen, TB391) using primers containing $5^{\prime} \mathrm{BamHI}$ and $3^{\prime}$ Not I restriction sites. Where indicated, a second copy of TJ10 was cloned into the second multiple cloning site of the vector using primers containing 5' NdeI and 3' KpnI restriction sites. Ligated DNA was transformed into XL1-Blue competent cells and amplified on LB plates containing kanamycin $(50 \mu \mathrm{g} / \mathrm{mL})$. Plasmids were verified by DNA sequencing.

Solubility Assays. Samples were prepared according to previous procedures. ${ }^{19}$ Briefly, BL21-Gold(DE3) cells (Agilent, \#230132) were transformed with the indicated construct/ $\mathrm{s}$ and grown overnight in terrific broth (TB, $5 \mathrm{~mL}$ ) with shaking at $37{ }^{\circ} \mathrm{C}$ in the presence of the appropriate antibiotics (ampicillin at $100 \mu \mathrm{g} / \mathrm{mL}$ and kanamycin at $50 \mu \mathrm{g} / \mathrm{mL}$ ). The 
optical density of each sample was measured at $600 \mathrm{~nm}$, and samples were diluted to an $\mathrm{OD}_{600}=0.1$ in $5 \mathrm{~mL}$. The cells were grown in a shaker at $37{ }^{\circ} \mathrm{C}$ until they reached an $\mathrm{OD}_{600}=$ 0.6-0.8 and were then induced with IPTG $(0.2 \mathrm{mM}$ final concentration). Small-molecule inhibitors were then added as indicated. The cells were subsequently incubated overnight, with shaking at $16{ }^{\circ} \mathrm{C}$. The next morning, the $\mathrm{OD}_{600}$ of the sample was measured and each culture was normalized to an $\mathrm{OD}_{600}=3.0$ in $1 \mathrm{~mL}$ of $\mathrm{TB}$, except in Figure $2 \mathrm{~b}$ where each culture was normalized to an $\mathrm{OD}_{600}=0.003$ in $1 \mathrm{~mL}$ of $\mathrm{TB}$ due to the use of the more-sensitive Nano-Glo Live Cell Assay reagent (see below). Cells were then harvested by centrifugation at $700 \mathrm{~g}$ for $10 \mathrm{~min}$ at $4{ }^{\circ} \mathrm{C}$ and resuspended in $200 \mu \mathrm{L}$ of $1 \times$ Nluc assay buffer $(50 \mathrm{mM}$ 2-ethanesulfonic acid (MES) $\mathrm{pH}=6.0,0.5 \mathrm{mM}$ ethylenediaminetetraacetic acid (EDTA), $75 \mathrm{mM} \mathrm{KCl,} 1 \mathrm{mM}$ 2-mercaptoethanol, and 17.5 $\mathrm{mM}$ thiourea) or $200 \mu \mathrm{L}$ of nanopure water when using the Nano-Glo Live Cell Assay reagent. The cells were then mixed with either $200 \mu \mathrm{L}$ of Nano-Glo Live Cell Assay reagent (Promega, N2011) prepared according to the manufacture's protocol or $200 \mu \mathrm{L}$ of $1 \times$ Nluc assay buffer containing either furimazine (Promega, N1110, 2\% v/v) or coelenterazine (GoldBio, CZ2.5, $25 \mu \mathrm{M}$ final concentration) as indicated. Relative changes in luminescence obtained in assays using either furimazine or coelenterazine are comparable. ${ }^{20}$ The resulting mixtures were then loaded into a 384-well assay plate (Corning, 3824, white, low volume, flat bottom, $40 \mu \mathrm{L}$ sample volume per well). Luminescence intensities were measured 30 min after addition of the substrate using a SynergyH1 hybrid reader (BioTek). Relative luminescence data are shown and represent the average of triplicate experiments conducted on three biological replicates. Error is reported as the standard deviation. Reported $p$-values were calculated using a two-tailed, unpaired $t$-test.

\section{ASSOCIATED CONTENT}

\section{s) Supporting Information}

The Supporting Information is available free of charge at https://pubs.acs.org/doi/10.1021/acsomega.0c00779.

One copy of TJ10 saturates the $\mathrm{A} \beta_{1-42}$ system; TJ10 may increase the solubility of amylin and $\mathrm{Htt} 97 \mathrm{Q}$; amino acid sequences for constructs (PDF)

\section{AUTHOR INFORMATION}

\section{Corresponding Author}

Cliff I. Stains - Department of Chemistry and Nebraska Center for Integrated Biomolecular Communication, University of Nebraska-Lincoln, Lincoln, Nebraska 68588, United States; Department of Chemistry and University of Virginia Cancer Center, University of Virginia, Charlottesville, Virginia 22904, United States; Cancer Genes and Molecular Regulation Program, Fred \& Pamela Buffet Cancer Center, University of Nebraska Medical Center, Omaha, Nebraska 68198, United States; ○ orcid.org/0000-0002-3165-4539; Email: cstains@ virginia.edu

\section{Authors}

Travis J. Nelson - Department of Chemistry, University of Nebraska-Lincoln, Lincoln, Nebraska 68588, United States Shuo Liang - Department of Chemistry, University of Nebraska-Lincoln, Lincoln, Nebraska 68588, United States;
Department of Chemistry, University of Virginia, Charlottesville, Virginia 22904, United States

Complete contact information is available at:

https://pubs.acs.org/10.1021/acsomega.0c00779

\section{Notes}

The authors declare no competing financial interest.

\section{ACKNOWLEDGMENTS}

This work was funded by the NIH (R35GM119751) and the University of Virginia. The content of this work is solely the responsibility of the authors and does not necessarily represent the official views of the NIH.

\section{REFERENCES}

(1) Chiti, F.; Dobson, C. M. Protein misfolding, functional amyloid, and human disease. Annu. Rev. Biochem. 2006, 75, 333-366.

(2) Lee, S. J. C.; Nam, E.; Lee, H. J.; Savelieff, M. G.; Lim, M. H. Towards an understanding of amyloid- $\beta$ oligomers: Characterization, toxicity mechanisms, and inhibitors. Chem. Soc. Rev. 2017, 46, 310323.

(3) Stains, C. I.; Mondal, K.; Ghosh, I. Molecules that target betaamyloid. ChemMedChem 2007, 2, 1674-1692.

(4) Knight, S. D.; Presto, J.; Linse, S.; Johansson, J. The BRICHOS Domain, Amyloid Fibril Formation, and Their Relationship. Biochemistry 2013, 52, 7523-7531.

(5) Ladiwala, A. R.; Bhattacharya, M.; Perchiacca, J. M.; Cao, P.; Raleigh, D. P.; Abedini, A.; Schmidt, A. M.; Varkey, J.; Langen, R.; Tessier, P. M. Rational design of potent domain antibody inhibitors of amyloid fibril assembly. Proc. Natl. Acad. Sci. U.S.A. 2012, 109, 19965-19970.

(6) Biancalana, M.; Koide, S. Molecular mechanism of Thioflavin-T binding to amyloid fibrils. Biochim. Biophys. Acta, Proteins Proteomics 1804, 2010, 1405-1412.

(7) Puchtler, H.; Sweat, F. Congo red as a stain for fluorescence microscopy of amyloid. J. Histochem. Cytochem. 1965, 13, 693-694.

(8) Puchtler, H.; Sweat, F.; Levine, M. On the Binding of Congo Red By Amyloid. J. Histochem. Cytochem. 1962, 10, 355-364.

(9) Westermark, G. T.; Johnson, K. H.; Westermark, P. Staining methods for identification of amyloid in tissue. Methods Enzymol. 1999, 309, 3-25.

(10) Meng, F.; Marek, P.; Potter, K. J.; Verchere, C. B.; Raleigh, D. P. Rifampicin does not prevent amyloid fibril formation by human islet amyloid polypeptide but does inhibit fibril thioflavin-T interactions: Implications for mechanistic studies of $\beta$-cell death. Biochemistry 2008, 47, 6016-6024.

(11) Maxwell, K. L.; Mittermaier, A. K.; Forman-Kay, J. D.; Davidson, A. R. A simple in vivo assay for increased protein solubility. Protein Sci. 1999, 8, 1908-1911.

(12) Waldo, G. S.; Standish, B. M.; Berendzen, J.; Terwilliger, T. C. Rapid protein-folding assay using green fluorescent protein. Nat. Biotechnol. 1999, 17, 691-695.

(13) Wigley, W. C.; Stidham, R. D.; Smith, N. M.; Hunt, J. F.; Thomas, P. J. Protein solubility and folding monitored in vivo structural complementation of a genetic marker protein. Nat. Biotechnol. 2001, 19, 131-136.

(14) Liu, Y.; Fares, M.; Dunham, N. P.; Gao, Z.; Miao, K.; Jiang, X.; Bollinger, S. S.; Boal, A. K.; Zhang, X. AgHalo: A Facile Fluorogenic Sensor to Detect Drug-Induced Proteome Stress. Angew. Chem., Int. Ed. 2017, 56, 8672-8676.

(15) Jung, K. H.; Kim, S. F.; Liu, Y.; Zhang, X. A Fluorogenic AggTag Method Based on Halo- and SNAP-Tags to Simultaneously Detect Aggregation of Two Proteins in Live Cells. ChemBioChem 2019, 20, 1078-1087.

(16) Kim, W.; Kim, Y.; Min, J.; Kim, D. J.; Chang, Y. T.; Hecht, M. H. A high-throughput screen for compounds that inhibit aggregation of the Alzheimer's peptide. ACS Chem. Biol. 2006, 1, 461-469. 
(17) McKoy, A. F.; Chen, J.; Schupbach, T.; Hecht, M. H. A novel inhibitor of amyloid $\beta$ (A $\beta)$ peptide aggregation: From high throughput screening to efficacy in an animal model of Alzheimer disease. J. Biol. Chem. 2012, 287, 38992-39000.

(18) Wurth, C.; Guimard, N. K.; Hecht, M. H. Mutations that reduce aggregation of the Alzheimer's A $\beta 42$ peptide: An unbiased search for the sequence determinants of $\mathrm{A} \beta$ amyloidogenesis. J. Mol. Biol. 2002, 319, 1279-1290.

(19) Nelson, T. J.; Zhao, J.; Stains, C. I. Utilizing split-NanoLuc luciferase fragments as luminescent probes for protein solubility in living cells. Methods Enzymol. 2019, 622, 55-66.

(20) Zhao, J.; Nelson, T. J.; Vu, Q.; Truong, T.; Stains, C. I. SelfAssembling NanoLuc Luciferase Fragments as Probes for Protein Aggregation in Living Cells. ACS Chem. Biol. 2016, 11, 132-138.

(21) Zhao, J.; Vu, Q.; Stains, C. I. Luminescent platforms for monitoring changes in the solubility of amylin and huntingtin in living cells. Mol. BioSyst. 2016, 12, 2984-2987.

(22) Nelson, T. J.; Truong, T.; Truong, B.; Bilyeu, C. V.; Zhao, J.; Stains, C. I. A luminescence-based assay for monitoring changes in alpha-synuclein aggregation in living cells. RSC Adv. 2020, 10, 16675-16678.

(23) Hall, M. P.; Unch, J.; Binkowski, B. F.; Valley, M. P.; Butler, B. L.; Wood, M. G.; Otto, P.; Zimmerman, K.; Vidugiris, G.; MacHleidt, T.; Robers, M. B.; Benink, H. A.; Eggers, C. T.; Slater, M. R.; Meisenheimer, P. L.; Klaubert, D. H.; Fan, F.; Encell, L. P.; Wood, K. $\mathrm{V}$. Engineered luciferase reporter from a deep sea shrimp utilizing a novel imidazopyrazinone substrate. ACS Chem. Biol. 2012, 7, 18481857.

(24) Tomabechi, Y.; Hosoya, T.; Ehara, H.; Sekine, S. I.; Shirouzu, M.; Inouye, S. Crystal structure of nanoKAZ: The mutated $19 \mathrm{kDa}$ component of Oplophorus luciferase catalyzing the bioluminescent reaction with coelenterazine. Biochem. Biophys. Res. Commun. 2016, 470, 88-93.

(25) Dixon, A. S.; Schwinn, M. K.; Hall, M. P.; Zimmerman, K.; Otto, P.; Lubben, T. H.; Butler, B. L.; Binkowski, B. F.; MacHleidt, T.; Kirkland, T. A.; Wood, M. G.; Eggers, C. T.; Encell, L. P.; Wood, K. V. NanoLuc Complementation Reporter Optimized for Accurate Measurement of Protein Interactions in Cells. ACS Chem. Biol. 2016, 11, 400-408.

(26) Machleidt, T.; Woodroofe, C. C.; Schwinn, M. K.; Mendez, J.; Robers, M. B.; Zimmerman, K.; Otto, P.; Daniels, D. L.; Kirkland, T. A.; Wood, K. V. NanoBRET-A Novel BRET Platform for the Analysis of Protein-Protein Interactions. ACS Chem. Biol. 2015, 10, 1797-1804.

(27) Abedini, A.; Meng, F.; Raleigh, D. P. A single-point mutation converts the highly amyloidogenic human islet amyloid polypeptide into a potent fibrillization inhibitor. J. Am. Chem. Soc. 2007, 129, $11300-11301$.

(28) Cheng, B.; Gong, H.; Li, X.; Sun, Y.; Zhang, X.; Chen, H.; Liu, X.; Zheng, L.; Huang, K. Silibinin inhibits the toxic aggregation of human islet amyloid polypeptide. Biochem. Biophys. Res. Commun. 2012, 419, 495-499.

(29) Gibrat, C.; Cicchetti, F. Potential of cystamine and cysteamine in the treatment of neurodegenerative diseases. Prog. NeuroPsychopharmacol. Biol. Psychiatry 2011, 35, 380-389.

(30) Dedeoglu, A.; Kubilus, J. K.; Jeitner, T. M.; Matson, S. A.; Bogdanov, M.; Kowall, N. W.; Matson, W. R.; Cooper, A. J.; Ratan, R. R.; Beal, M. F.; Hersch, S. M.; Ferrante, R. J. Therapeutic effects of cystamine in a murine model of Huntington's disease. J. Neurosci. 2002, 22, 8942-8950.

(31) Fox, J. H.; Barber, D. S.; Singh, B.; Zucker, B.; Swindell, M. K.; Norflus, F.; Buzescu, R.; Chopra, R.; Ferrante, R. J.; Kazantsev, A.; Hersch, S. M. Cystamine increases L-cysteine levels in Huntington's disease transgenic mouse brain and in a PC12 model of polyglutamine aggregation. J. Neurochem. 2004, 91, 413-422.

(32) Krobitsch, S.; Lindquist, S. Aggregation of huntingtin in yeast varies with the length of the polyglutamine expansion and the expression of chaperone proteins. Proc. Natl. Acad. Sci. U.S.A. 2000, 97, 1589-1594.
(33) Bennett, M. J.; Huey-Tubman, K. E.; Herr, A. B.; West, A. P., Jr.; Ross, S. A.; Bjorkman, P. J. A linear lattice model for polyglutamine in CAG-expansion diseases. Proc. Natl. Acad. Sci. U.S.A. 2002, 99, 11634-11639.

(34) Li, S. H.; Li, X. J. Aggregation of N-terminal huntingtin is dependent on the length of its glutamine repeats. Hum. Mol. Genet. 1998, 7, 777-782.

(35) Smith, T. J.; Stains, C. I.; Meyer, S. C.; Ghosh, I. Inhibition of $\beta$-amyloid fibrillization by directed evolution of a $\beta$-sheet presenting miniature protein. J. Am. Chem. Soc. 2006, 128, 14456-14457.

(36) Malakauskas, S. M.; Mayo, S. L. Design, structure and stability of a hyperthermophilic protein variant. Nat. Struct. Biol. 1998, 5, 470475 .

(37) Kayed, R.; Head, E.; Thompson, J. L.; McIntire, T. M.; Milton, S. C.; Cotman, C. W.; Glabe, C. G. Common structure of soluble amyloid oligomers implies common mechanism of pathogenesis. Science 2003, 300, 486-489.

(38) Tavassoli, A. SICLOPPS cyclic peptide libraries in drug discovery. Curr. Opin. Chem. Biol. 2017, 38, 30-35.

(39) Townend, J. E.; Tavassoli, A. Traceless Production of Cyclic Peptide Libraries in E. coli. ACS Chem. Biol. 2016, 11, 1624-1630.

(40) Scott, C. P.; Abel-Santos, E.; Wall, M.; Wahnon, D. C.; Benkovic, S. J. Production of cyclic peptides and proteins in vivo. Proc. Natl. Acad. Sci. U.S.A. 1999, 96, 13638-13643.

(41) Tavassoli, A.; Benkovic, S. J. Split-intein mediated circular ligation used in the synthesis of cyclic peptide libraries in E. coli. Nat. Protoc. 2007, 2, 1126-1133. 